\title{
The consultation and physical examination
}

Since Michael Balint in the 1950s much reflection and comment has occurred on the concept of the consultation. ${ }^{1}$ Now cohort after cohort of medical students benefit from ever greater exposure to communication ideas leaving their more qualified colleagues running to catch up. Little, though, has been said about the physical examination. This is remarkable. The physical examination forms part of our earliest clinical experience but has had little focus in my professional development since then. I believe that the evolution in our communication skills has more to contribute to the physical examination of our patients and the physical examination has more to contribute to the consultation than is commonly identified.

Balint said 'Our patients are trained from childhood to expect a more or less thorough physical examination." Patients intermingle telling their story and the doctor's examination, and see these as two parts of a whole. I examine sometimes to meet patient expectation. Although there are patients who prepare for a physical examination (going home to wash) and I only identify this as I am closing the consultation, how many others will have left without this expectation being understood and met? But a physical examination does more than address patient expectation.

\section{DIAGNOSIS}

The acknowledged significance of physical examination is in finding physical signs. There are decades of medical undergraduate education committed to this. Although the 'thorough physical examination' was a 20th century phenomenon, before that, 'the physician's job was not hands on: what counted were book learning, experience, memory, judgement and a good bedside manner'. ${ }^{2}$

\section{RELATIONSHIP BUILDING AND INFORMATION GATHERING}

In the diagrammatic representation of the Cambridge Calgary model $^{3}$ of the consultation, relationship building is threaded throughout the encounter. This seems to suggest that the communication that occurs between the doctor and the patient at all stages of the consultation, including the physical examination, contributes to the relationship: developing rapport or connecting. Neighbour talks about using minimal cues and eliciting information, '.. beyond the purely clinical to encompass the psychological, social, and family factors ...', and discusses the when, what, and how of eliciting. ${ }^{4} \mathrm{He}$ suggests there are no rules but that we should 'do what works'.

- As I passed a speculum for abnormal vaginal bleeding, Selina asked whether this could be cancer. She chose the moment to ask the question. It seemed important to respond to it, when she was thinking of it.

- George, a bus driver, had been sent by our practice nurse because his blood pressure was raised. He had the feeling of a sent man. It wasn't easy to connect. $\mathrm{He}$ was holding something back. Silences and open questions were not enough. I fell back on history and physical examination. With his shirt sleeve rolled up, stethoscope in my ears and my hand on his arm he said, 'I don't want to lose my job'. I am not clear if the physical touch allowed him to share his fear with me or that silence gave him the space to let this thought surface. 'Lose your job ...', and I waited.

\section{THERAPEUTIC}

The New Testament has a strong thread of healing with the laying on of hands. So for millennia people have identified touch with healing. Empathy comes from the Greek, meaning 'physical affection'. This elusive concept seems to be about understanding and identifying with another in such a way that they feel understood and identified with. Could the touch of the examination contribute here? Is knowing that the physical examination has been done and is normal, therapeutic? Balint suggested that 'the most frequently used drug in general practice was the doctor himself'. 'Is the doctor as the drug more effective when touch is included?

- Joe came with chest pain. We considered the history together. It did not suggest cardiac pain despite his extensive list of risk factors. As I examined him he mentioned his wife, her depression and his concern for her. I listened to his feelings. We made a plan and as he left he shook my hand in both of his and left. It felt like a therapeutic alliance. $^{5}$

\section{THE PSYCHOSEXUAL CONSULTATION}

Some doctors, caring for patients with sexual problems, have long recognised that the physical examination has more value than just looking for physical signs. The Institute of Psychosexual Medicine $(\text { IPM })^{6}$ suggests that the physical examination becomes a psychosomatic event where body and mind can be studied together; that the physical examination is not just to exclude physical disease but that 'defences may be discarded along with clothing'. ' Where rapport may be developed, where information may be heard and explored, and where a shared understanding may be developed. Need this skill only be used in psychosexual consultations? There is room for debate. Launer $^{8}$ and others have expressed concern about seeking 'revealing personal information' at the time of (vaginal) examinations. Neighbour says, 'Let nothing escape your notice'. Would he be happy to apply 'do what works' here?

- Sheila told me she was uninterested in sex. She and her husband had had a loving sex life for decades and recently she just couldn't be bothered. I wondered about the menopause and atrophy and suggested an examination. She got up on the couch easily and 
seemed comfortable with her body. As I looked at her genital area she started telling me of their family difficulties. I stopped what I was doing; concentrating on what she was prioritising, and listened. The family business had gone bankrupt. And her husband wasn't the same 'He is not the man he was', I thought she meant that he too was struggling with sex and waited for her to tell me more. Instead she told me that for her somehow he was diminished by the bankruptcy. She was very quiet now ... and rather ashamed. She wasn't proud of this feeling but it was the truth and understanding it seemed to relieve her.

- Sophie had lost interest in sex since before her baby. She wasn't sure she had healed up. I suggested an examination and was surprised with her response 'No, I haven't got time.' 'Or maybe you just don't want an examination ... perhaps in the same way you don't want sex.' 'Well I think of myself as a mother now ...' And out tumbled out ideas about how important it was for her to be a good mother, how she had to let her husband change nappies even though he wasn't any good at it. Sophie may have let these ideas come to mind at another moment but something about turning the doctor away let her understand how she was only living her role as a mother.

These patients are all real, but not identifiable. All doctors tell stories of patients: 'giving the history'. Many writers and medical communities use narratives to contribute to an understanding of the consultation for good reason. Qualitative research as described by Sweeny suggests that 'the notion of truth is not absolute, but rather it resides in gaining an understanding of an individual's frame of reference by acquiring a detailed knowledge of their views, attitudes, and beliefs'. 9 Pendleton says, 'Doctors relate statistics but without the persuasive force of the stories patients tell. ${ }^{10}$ Narrativebased medicine goes further to suggest that using these stories may help 'the patient to develop a new story'. ${ }^{8}$

\section{CONCLUSION}

The physical examination (touching the patient) is no less complex than other aspects of the consultation and deserves more attention. More could and should and probably does occur during it than we give thought to. Patients with sexual problems have been noted to share relevant information at the time of the genital examination and those doctors involved in their care have been trained to be vigilant to this and to use this shared information to further the doctor-patient relationship or therapeutic alliance. I believe that our patients trust us to use all our professional skills throughout the consultation. When they offer us something, in whatever way and at whatever point of the consultation, our duty is to attend to it and respond to it.

\section{Alexandra L Connan}

All the cases mentioned in this essay have been anonymised by the author.

\section{REFERENCES}

1. Balint M. The doctor his patient and the illness. 2nd edn. Edinburgh: Churchill Livingstone, 1964

2. Porter R. Blood and guts. London: Penguin Group, 2002.

3. Silverman J, Kurtz S, and Draper J. Skills for communicating with patients. 2nd edn. Oxford: Radcliffe Publishing, 2005.

4. Neighbour R. The inner consultation. 2nd edn. Oxford: Radcliffe Publishing, 2005.

5. Mead N, Bower P. Patient-centredness: a conceptual framework and review of the empirical literature. $S o c$ Sci Med 2000; 51(7): 1087-1110.

6. Institute of Psychosexual Medicine. Prospectus for the Institute of Psychosexual Medicine. London: IPM 2004. http://www.ipm.org.uk (accessed 28 Apr 2009)

7. Skrine R, and Montford H. Psychosexual medicine: an introduction. 2nd edn. London: Arnold, 2001.

8. Launer J. Narrative-based primary care a practical guide. Oxford: Radcliffe Medical Press, 2002.

9. Sweeney K. Complexity in primary care: understanding its value. Oxford: Radcliffe Publishing, 2006.

10. Pendleton D, Schofield T, Tate P, Havelock P. The new consultation. Oxford: Oxford Medical Publications, 2003.

DOI: 10.3399/bjgp09X453639 